\title{
Faktor Risiko Penyebab Anemia pada Ibu Hamil di Puskesmas Makale Tahun 2016
}

\author{
Sumarce Bongga ${ }^{1}$ \\ 1.*Akademi Kebidanan Sinar Kasih, Jl. Pongtiku No.157, Kab. Tana Toraja, Indonesia, Kode Pos 91811 \\ *e-mail: sumarcebongga2018@mail.com
}

\begin{abstract}
Anemia in pregnancy can adversely affect pregnant women especially during pregnancy. This study aims to determine the risk factors causing anemia in pregnant women at Makale Health Center. This research is analytic observational research with case control design. Cases were pregnant women who went to Makale health center and experienced anemia based on laboratory results. Controls were pregnant women who went to Makale health center and did not experience anemia based on laboratory results. The number of samples in the study were 108 pregnant women consisting 54 cases and 54 controls. Data processing using SPSS program with Odds Ratio and multiple logistic regression. The results showed the prevalence of anemia at Makale Community Health Center by 63\%. Compliance with Fe tablets, parity and gestational distance are risk factors for anemia in pregnant women. The variables most associated with anemia in pregnant women are adherence to taking Fe tablets. This study suggests that pregnant women routinely consume Fe tablets to avoid anemia, mothers who have parity $\geq 4$ diligent pregnancy check to monitor the health of the fetus and mother, In order for EFA to pay attention to the distance pregnancy in planning the next pregnancy.
\end{abstract}

Keywords : Anemia, fe tablet, gestational distance, pregnant mother

\begin{abstract}
Abstrak
Anemia dalam kehamilan dapat berpengaruh buruk pada ibu hamil terutama saat kehamilan. Penelitian ini bertujuan untuk mengetahui faktor risiko penyebab terjadinya anemia pada Ibu hamil Di Puskesmas Makale. Penelitian ini adalah penelitian observasional analitik dengan rancangan case control. Kasus adalah ibu hamil yang memeriksakan ke puskesmas Makale dan mengalami anemia berdasarkan hasil laboratorium. Kontrol adalah ibu hamil yang memeriksakan ke puskesmas Makale dan tidak mengalami anemia berdasarkan hasil laboratorium. Jumlah sampel dalam penelitian sebanyak 108 ibu hamil yang terdiri 54 kasus dan 54 kontrol. Pengolahan data menggunakan program SPSS dengan Odds Rasio dan regresi logistik berganda. Hasil penelitian menunjukkan kepatuhan mengkonsumsi tablet $\mathrm{Fe}$, paritas, dan jarak kehamilan merupakan faktor risiko terhadap kejadian anemia pada ibu hamil di Puskesmas Makale tahun 2016. Kepatuhan mengkonsumsi tablet Fe, paritas dan jarak kehamilan merupakan faktor risiko terjadinya anemia pada ibu hamil. Variabel yang paling berhubungan dengan anemia pada ibu hamil adalah kepatuhan mengkonsumsi tablet $\mathrm{Fe}$. Penelitian ini menyarankan agar ibu hamil rutin megkonsumsi tablet $\mathrm{Fe}$ agar terhindar dari anemia, Ibu yang mempunyai paritas $\geq 4$ rajin memeriksakan kehamilannya untuk memantau kesehatan janin dan ibunya, Agar PUS memperhatikan jarak kehamilan dalam merencanakan kehamilan berikutnya.
\end{abstract}

Kata kunci : Anemia, jarak kehamilan, ibu hamil, tablet fe 


\section{Pendahuluan}

Anemia pada kehamilan merupakan masalah yang umum karena mencerminkan nilai kesejahteraan sosial ekonomi masyarakat dan pengaruhnya sangat besar terhadap kualitas sumber daya manusia. Anemia hamil disebut "Potensial danger of mother and child" (potensial membahayakan ibu dan anak), karena itulah anemia memerlukan perhatian serius dari semua pihak yang terkait dalam pelayanan kesehatan pada hari terdepan. Anemia dalam kehamilan memberikan pengaruh yang kurang baik bagi ibu, baik dalam kehamilan, persalinan, maupun dalam nifas. Berbagai penyakit dapat timbul akibat anemia seperti abortus, partus prematur, partus lama, akibat insersi uteri, perdarahan post partum karena atonia uteri, syok, infeksi baik intra partum maupun post partum (Manuaba, 2010).

Anemia pada kehamilan juga berhubungan dengan meningkatnya kesakitan ibu. Anemia karena defisiensi zat besi merupakan penyebab utama anemia ibu hamil dibandingkan dengan defisiensi zat gizi lainnya. Oleh karena itu anemia gizi pada masa kehamilan sering diidentikkan dengan anemia gizi besi. Kebanyakan anemia disebabkan oleh defisiensi zat besi dan perdarahan akut, bahkan tidak jarang keduanya saling berinteraksi (Sarwono, 2000).

Keadaan kekurangan besi pada ibu hamil dapat menimbulkan gangguan atau hambatan pada pertumbuhan baik pada sel tubuh maupun sel otak. Pada ibu hamil dapat mengalami keguguran, lahir sebelum waktunya, bayi berat lahir rendah (BBLR), perdarahan sebelum serta pada waktu melahirkan dan pada anemia berat yang dapat menimbulkan kematian ibu dan bayi. Pada anak dapat mengalami gangguan pertumbuhan, tidak dapat mencapai tinggi yang optimal dan anak menjadi kurang cerdas (Soekirman, 2000).

Pemerintah telah melakukan upaya-upaya untuk menurunkan prevalensi kejadian anemia ibu hamil . Departemen Kesehatan telah mengembangkan strategi jangka panjang penanggulangan anemia di Indonesia. Strategi operasionalnya diharapkan pada empat macam kegiatan yaitu : KIE (Komunikasi Informasi Edukasi), Suplementasi, Fortifikasi dan kegiatan lintas sektoral yang sejalan. Untuk menurunkan prevalensi anemia sebesar 33\% maka peran utama ada di tangan suplementasi dan dalam pelaksanaannya telah dilakukan dengan mendistribusikan tablet tambah darah yang berisi zat besi disertai dengan unsur Gizi lainnya pada ibu hamil (Depkes RI, 2015).

Anemia pada masa kehamilan merupakan masalah kesehatan yang paling penting dalam upaya meningkatkan derajat kesehatan masyarakat sehubungan dengan kesehatan ibu dan anak. Anemia adalah salah satu faktor yang menjadi indiktor keberhasilan pembangunan kesehatan suatu bangsa, yang menggambarkan kemampuan sosial ekonomi dalam memenuhi kebutuhan kualitas dan kuantitas gizi masyarakat (Arisman, 2009).

Menurut data Riskesdas (2013), ibu hamil yang mengalami anemia sebesar 37,1\% dan prevalensinya hampir sama antara bumil diperkotaan $(36,4 \%)$ dan perdesaan $(37,8 \%)$. Hal ini menunjukkan angka tersebut mendekati masalah kesehatan masyarakat berat (severe public health problem) dengan batas prevalensi anemia lebih dari 40\% (BPPK, 2014).

Data Dinas Kesehatan Tana Toraja menyebutkan bahwa kasus anemia di TanaToraja sebanyak 695 kasus (47\%) pada tahun 2015, sedangkan jumlah ibu hamil yang mengalami anemia di puskesmas Makale tahun 2016 sebanyak 55 orang $(43,6 \%)$.

Faktor perilaku dan psikologis ibu hamil dan kehamilan jarak dekat rentan mengakibatkan maternal depletion syndrome, yakni terjadinya pengikisan nutrisi ibu oleh janin. Baru saja melahirkan, disambung kehamilan lagi, membuat ibu tak memiliki cukup waktu untuk mengembalikan cadangan nutrisi. Kehamilan jarak dekat juga bisa mengakibatkan kelahiran prematur, penyusutan air susu ibu, bahkan setelah bayi lahir bisa terjadi persaingan antar saudara. Dibanding dengan jarak kelahiran yang kurang dari dua tahun setelah kelahiran sebelumnya, anak-anak yang dilahirkan dengan interval kehamilan 3-4 tahun memiliki kelangsungan hidup lebih lama secara signifikan, yaitu sekitar 1,5 kali lebih tinggi selama minggu pertama kehidupannya. 2,2 kali lebih tinggi selama 28 hari pertama kehidupannya 2,3 kali lebih tinggi selama setahun pertama kehidupannya. 2,4 kali lebih tinggi selama masa balita. Jarak kehamilan lebih panjang setelah kelahiran terakhir, juga membuat ibu dan anak lebih sehat. Orang tua bisa mencurahkan waktu lebih banyak bagi anak di usia awal mereka. Orang tua pun lebih banyak waktu untuk melakukan aktivitas di luar rumah, baik bagi pengembangan diri mereka, maupun untuk menguatkan kondisi finansial keluarga (Mother And Baby, 2007).

Masalah anemia pada masa kehamilan merupakan masalah penting untuk ditanggulangi sedini mungkin. Oleh karena itu, untuk mencegah meningkatnya kejadian anemia pada ibu masa hamil, maka dalam penelitian ini akan mencari faktor-faktor yang berisiko pernyebab terjadinya anemia ibu hamil di puskesmas Makale.

\section{Metode}

Jenis penelitian ini digunakan adalah penelitian observasional analitik dengan pendekatan case control study. pen kasus-kontol adalah jenis penelitian epidemiology yang mempelajari hubungan faktor risiko dengan akibatnya dengan cara membandingkan antara kelompok kasus dengan kelompok kontrol. Skema penentuan kasus dan kontrol yang dilakukan pada penetapan kasus berdasarkan hasil pemeriksaan laboratorium yang ada pada buku KIA ibu hamil, selanjutnya ditelusuri secara retrospektif mengenai identitas pasien sesuai tujuan penelitian, baik kasus maupun kontrol. 
Tahap selanjutnya yaitu melakukan wawancara dengan menggunakan kuesioner yang telah disiapkan. Adapun skema rancangan sebagai berikut:

Lokasi penelitian yang dipilih adalah Puskesmas Makalae. Penelitian ini akan dilaksanakan pada bulan AgustusSeptember 2016

Populasi dan Sampel

1. Populasi 2016.

Populasi pada penelitian ini adalah seluruh ibu hamil yang memeriksakan diri di Puskesmas Makale tahun

2. Sampel

a. Kasus adalah ibu hamil yang memeriksakan ke puskesmas Makale dan mengalami anemia berdasarkan hasil laboratorium

b. Kontrol adalah ibu hamil yang memeriksakan ke puskesmas Makale dan tidak mengalami anemia berdasarkan hasil laboratorium

3. Besar Sampel

Berdasarkan perhitungan, diperoleh sampel minimal sebesar 54 responden. Sampel ditetapkan dengan perbandingan 1:1 sehingga ditetapkan 54 kasus dan 54 kontrol. Jumlah keseluruhan sampel kasus dan kontrol adalah 108 responden.

Sampel ditarik dari populasi asal dengan menggunakan teknik purposive sampling yakni menarik anggota populasi yang memenuhi kriteria sampel yang telah ditentukan.

Kriteria Sampel

1. Kriteria Inklusi

a. Ibu dengan kehamilan 13-36 minggu

b. Ibu hamil yang bersedia menjadi responden

c. Ibu hamil yang berdomisili di wilayah Puskesmas Makale

2. Kriteria Eksklusi

a. Ibu hamil yang tidak diperiksa Hbnya

b. Hamil ganda

Analisis Data

Data yang telah terkumpul selanjutnya diolah untuk kemudian dianalisis sebagai berikut:

1. Analisis Univariat

Analisis univariat dimaksudkan untuk memperbaiki distribusi frekuensi dan presentase tunggal yang terkait dengan tujuan penelitian.

2. Analisis Bivariat

Analisis bivariat bertujuan melihat besar risiko variabel independen terhadap variabel dependen. Mengingat rancangan penelitian ini adalah studi case control, maka analisis hubungan dilakukan dengan menggunakan perhitungan Odds Ratio (OR) yang dilakukan dengan menggunakan tabulasi silang antar variabel. Dengan diketahuinya nilai OR, memungkinkan untuk memprediksi hubungan dari fakta yang diteliti terhadap kematian perinatal.

\section{Hasil}

Penelitian ini dilakukan di puskesmas Makale mulai tanggal 1 Agustus sampai 30 September 2016. Penelitian ini bertujuan untuk mengetahui prevalensi dan faktor risiko kepatuhan mengkonsumsi tablet Fe, paritas, jarak kehamilan pada ibu hamil, umur, pendidikan. Jumlah sampel dalam penelitian sebanyak 108 ibu hamil yang terdiri dari 54 kasus dan 54 kontrol.

Pengumpulan data primer menggunakan kuesioner yang diisi langsung oleh responden, kemudian diolah dan disajikan dalam bentuk table frekuensi dan crosstab (tabulasi silang) sesuai dengan penelitian disertai narasi sebagai penjelasan table dan variable dalam penelitian dianalisis secara univariat, bivariat, dan multivariate. Adapun hasil penelitian diuraikan sebagai berikut : 
Tabel 1. Distribusi responden menurut kelompok umur ibu hamil di puskesmas makale tahun 2016

\begin{tabular}{ccc}
\hline Umur & Frekuensi & Persentase (\%) \\
\hline $20-24$ & 17 & 15,7 \\
$25-29$ & 35 & 32,4 \\
$30-34$ & 26 & 24,1 \\
$35-39$ & 21 & 19,4 \\
$40-44$ & 9 & 8,3 \\
\hline Total & 108 & 100,0 \\
\hline
\end{tabular}

Tabel .1 menjelaskan bahwa karakteristik responden berdasarkan kelompok umur tertinggi pada ibu hamil yaitu kelompok umur 25-29 tahun sebesar 32,4\% dan terendah pada kelompok usia 40-44 tahun sebesar 8,3\%.

Tabel 2. Distribusi responden menurut kelompok pendidikan ibu hamil di puskesmas makale tahun 2016

\begin{tabular}{ccc}
\hline Pendidikan & Frekuensi & Persentase (\%) \\
\hline SLTP & 3 & 2,8 \\
SLTA & 54 & 50,0 \\
Diploma & 29 & 26,9 \\
Sarjana & 22 & 20,4 \\
\hline Total & 108 & 100,0 \\
\hline
\end{tabular}

Tabel .2 menjelaskan bahwa karakteristik responden berdasarkan kelompok pendidikan yaitu, tertinggi pada kelompok pendidikan SLTA sebesar 50,0\% dan terendah pada kelompok pendidikan SLTP sebesar 2,8\%.

Tabel 3. Distribusi responden menurut kelompok pekerjaan ibu hamil di puskesmas makale tahun 2016

\begin{tabular}{ccc}
\hline Pekerjaan & Frekuensi & Persentase (\%) \\
\hline IRT & 64 & 59,3 \\
PNS & 20 & 18,5 \\
Swasta & 3 & 2,8 \\
Honorer & 21 & 19,4 \\
\hline Total & 108 & 100,0 \\
\hline
\end{tabular}

Tabel 3 menjelaskan bahwa karakteristik responden berdasarkan pekerjaan tertinggi pada kelompok IRT sebesar 59,3\% dan terendah pada kelompok pekerja swasta sebesar $2,8 \%$.

Tabel 4. Distribusi responden menurut kelompok kepatuhan minum tablet fe ibu hamil di puskesmas makale tahun 2016

\begin{tabular}{ccc}
\hline Kepatuhan & Frekuensi & Persentase (\%) \\
\hline Risiko Tinggi & 72 & 66,7 \\
Risiko rendah & 36 & 33,3 \\
\hline Total & 108 & 100,0 \\
\hline
\end{tabular}

Tabel 4. menjelaskan bahwa kepatuhan minum tablet Fe pada ibu hamil tertinggi pada ibu hamil yang tidak patuh sebesar $66,7 \%$ dan terendah pada ibu hamil yang patuh sebesar 33,3\%.

Tabel 5. Distribusi responden menurut kelompok paritas ibu hamil di puskesmas makale tahun 2016

\begin{tabular}{ccc}
\hline Pariras & Frekuensi & Persentase (\%) \\
\hline Risiko tinggi & 61 & 56,5 \\
Risiko rendah & 47 & 43,5 \\
\hline Total & 108 & 100,0 \\
\hline
\end{tabular}


Tabel 5 menjelaskan bahwa berdasarkan kelompok paritas ibu hamil yang memiliki risiko tinggi sebesar 56,5\% dan risiko rendah sebesar 43,5.

Tabel 6. Distribusi responden jarak kehamilan pada ibu hamil di puskesmas makale tahun 2016

\begin{tabular}{ccc}
\hline Jarak Kehamilan & Frekuensi & Persentase (\%) \\
\hline Risiko Tinggi & 78 & 72,2 \\
Risiko rendah & 30 & 27,8 \\
\hline Total & 108 & 100,0 \\
\hline
\end{tabular}

Tabel .6 menjelaskan bahwa jarak kehamilan pada ibu hamil tertinggi pada kelompok risiko tinggi sebesar $72,2 \%$ dan pada kelompok risiko rendah $27,8 \%$.

Tabel 7. Faktor risiko kepatuhan mengkonsumsi tablet fe terhadap kejadian anemia pada ibu hamil di puskesmas makale tahun 2016

\begin{tabular}{|c|c|c|c|c|c|c|c|}
\hline \multirow{3}{*}{ Kepatuhan } & \multicolumn{4}{|c|}{ Status } & \multirow{3}{*}{ OR } & \multirow{3}{*}{ Sig } & \multirow{3}{*}{ CI } \\
\hline & \multicolumn{2}{|c|}{ Kasus } & \multicolumn{2}{|c|}{ Kontrol } & & & \\
\hline & $\mathbf{n}$ & $\%$ & $\mathbf{n}$ & $\%$ & & & \\
\hline Tidak Patuh & 44 & 81,5 & 28 & 51,9 & \multirow{2}{*}{4,086} & \multirow{2}{*}{0,001} & \multirow{2}{*}{$1,712-9,749$} \\
\hline Patuh & 10 & 18,5 & 26 & 48,1 & & & \\
\hline Jumlah & 54 & 100 & 54 & 100 & & & \\
\hline
\end{tabular}

Tabel .7 menjelaskan bahwa dari 54 responden yang menderita filariasis (kasus) terdapat $44(81,5 \%)$ yang tidak patuh mengkonsumsi tablet Fe dan 10 (18,5\%) yang patuh mengkonsumsi tablet Fe. Sedangkan dari 54 yang tidak menderita (kontrol) terdapat $28(51,9 \%)$ yang tidak patuh mengkonsumsi tablet Fe dan $26(48,1 \%)$ yang patuh mengkonsumsi tablet Fe. Nilai OR sebesar 4,086 yang menunjukkan bahwa tidak patuh mengkonsumsi tablet Fe berisiko 4,086 kali untuk menderita anemia.

Tabel 8. Faktor risiko paritas terhadap kejadian anemia pada ibu hamil di puskesmas makale tahun 2016

\begin{tabular}{|c|c|c|c|c|c|c|c|}
\hline \multirow{3}{*}{ Paritas } & \multicolumn{4}{|c|}{ Status } & \multirow{3}{*}{ OR } & \multirow{3}{*}{ Sig } & \multirow{3}{*}{ CI } \\
\hline & \multicolumn{2}{|c|}{ Kasus } & \multicolumn{2}{|c|}{ Kontrol } & & & \\
\hline & n & $\%$ & n & $\%$ & & & \\
\hline Risiko tinggi & 36 & 66,7 & 25 & 46,3 & \multirow{2}{*}{2,320} & \multirow{2}{*}{0,033} & \multirow{2}{*}{$1,065-5,054$} \\
\hline Risiko rendah & 18 & 33,3 & 29 & 53,7 & & & \\
\hline Jumlah & 54 & 100 & 54 & 100 & & & \\
\hline
\end{tabular}

Tabel .8 menjelaskan bahwa dari 54 penderita (kasus) terdapat 36 (66,7\%) yang memiliki risiko tinggi terhadap kejadian anemia pada ibu hamil dan $18(33,3 \%)$ yang memiliki risiko rendah terhadap kejadian anemia pada ibu hamil. Sedangkan dari 54 yang bukan penderita (kontrol) terdapat 25 (46,3\%) yang memiliki risiko tinggi terhadap kejadian anemia pada ibu hamil dan $29(53,7 \%)$ yang memiliki risiko rendah terhadap kejadian anemia pada ibu hamil. Nilai OR sebesar 2,320 yang menunjukkan bahwa paritas yang memiliki risiko tinggi 2,320 berisiko untuk menderita anemia.

Tabel 9. Faktor risiko jarak kehamilan terhadap kejadian anemia pada ibu hamil di puskesmas makale tahun 2016

\begin{tabular}{|c|c|c|c|c|c|c|c|}
\hline \multirow{3}{*}{$\begin{array}{c}\text { Jarak } \\
\text { Kehamilan }\end{array}$} & \multicolumn{4}{|c|}{ Status } & \multirow{3}{*}{ OR } & \multirow{3}{*}{ Sig } & \multirow{3}{*}{ CI } \\
\hline & \multicolumn{2}{|c|}{ Kasus } & \multicolumn{2}{|c|}{ Kontrol } & & & \\
\hline & $\mathbf{n}$ & $\%$ & n & $\%$ & & & \\
\hline Risiko tinggi & 45 & 83,3 & 33 & 61,1 & \multirow{2}{*}{3,182} & \multirow{2}{*}{0,010} & \multirow{2}{*}{$1,293-7,833$} \\
\hline Risiko rendah & 9 & 16,7 & 21 & 38,9 & & & \\
\hline Jumlah & 54 & 100 & 54 & 100 & & & \\
\hline
\end{tabular}


Tabel 9 menjelaskan bahwa dari 54 penderita (kasus) terdapat $45(83,3 \%)$ yang memiliki risiko tinggi terhadap kejadian anemia pada ibu hamil dan $9(16,7 \%)$ yang memiliki risiko rendah terhadap kejadian anemia pada ibu hamil. Sedangkan dari 54 yang bukan penderita (kontrol) terdapat $33(61,1 \%)$ yang memiliki risiko tinggi terhadap kejadian anemia pada ibu hamil dan $21(38,9 \%)$ yang memiliki risiko rendah. Nilai OR sebesar 3,182 yang menunjukkan bahwa jarak kehamilan yang memiliki risiko tinggi 3,182 kali berisiko untuk menderita anemia.

Tabel 10. Distribusi responden menurut umur terhadap kejadian anemia pada ibu hamil di puskesmas makale tahun 2016

\begin{tabular}{|c|c|c|c|c|c|c|c|}
\hline \multirow{3}{*}{ Umur } & \multicolumn{4}{|c|}{ Status } & \multirow{3}{*}{$\mathbf{O R}$} & \multirow{3}{*}{ Sig } & \multirow{3}{*}{ CI } \\
\hline & \multicolumn{2}{|c|}{ Kasus } & \multicolumn{2}{|c|}{ Kontrol } & & & \\
\hline & $\mathbf{n}$ & $\%$ & n & $\%$ & & & \\
\hline$>20$ thn & 52 & 96,3 & 50 & 92,6 & \multirow{2}{*}{2,080} & \multirow{2}{*}{0,401} & \multirow{2}{*}{$0,365-11,865$} \\
\hline$<20$ thn & 2 & 3,7 & 4 & 7,4 & & & \\
\hline Jumlah & 54 & 100 & 54 & 100 & & & \\
\hline
\end{tabular}

Tabel .10 menjelaskan bahwa dari 54 penderita (kasus) terdapat 52 (96,3\%) yang memiliki umur >20 tahun dan 2 $(33,3 \%)$ yang memiliki umur $<20$ tahun. Sedangkan dari 54 yang bukan penderita (kontrol) terdapat 48 (48,5\%) yang memiliki umur $>20$ tahun dan $2(33,3 \%)$ yang memiliki umur <20 tahun. Nilai OR sebesar 2,080 yang menunjukkan bahwa umur 2,080 kali protektif untuk menderita anemia.

Tabel. 11 Distribusi responden menurut pendidikan terhadap kejadian anemia pada ibu hamil di puskesmas makale tahun 2016

\begin{tabular}{|c|c|c|c|c|c|c|c|}
\hline \multirow{3}{*}{ Pendidikan } & \multicolumn{4}{|c|}{ Status } & \multirow{3}{*}{$\mathbf{O R}$} & \multirow{3}{*}{ Sig } & \multirow{3}{*}{ CI } \\
\hline & \multicolumn{2}{|c|}{ Kasus } & \multicolumn{2}{|c|}{ Kontrol } & & & \\
\hline & $\mathbf{n}$ & $\%$ & $\mathbf{n}$ & $\%$ & & & \\
\hline Rendah & 28 & 51,9 & 23 & 42,6 & \multirow{2}{*}{1,452} & \multirow{2}{*}{0,335} & \multirow{2}{*}{$0,680-3,100$} \\
\hline Tinggi & 26 & 48,1 & 31 & 57,4 & & & \\
\hline Jumlah & 54 & 100 & 54 & 100 & & & \\
\hline
\end{tabular}

Tabel .11 menjelaskan bahwa dari 54 penderita (kasus) terdapat $28(51,9 \%)$ yang memiliki pendidikan rendah dan 26 $(48,1 \%)$ yang memiliki pendidikan tinggi. Sedangkan dari 54 yang bukan penderita (kontrol) terdapat $23(42,6 \%)$ yang memiliki pendidikan rendah dan 31 (57,4\%) yang memiliki pendidikan tinggi. Nilai OR sebesar 1,452 yang menunjukkan bahwa pendidikan merupakan faktor risiko untuk menderita anemia.

Tabel 12. Kepatuhan mengkonsumsi tablet fe, paritas, dan jarak kehamilan terhadap kejadian anemia pada ibu hamil di puskesmas makale tahun 2016

\begin{tabular}{ccccc}
\hline Variabel & OR & Sig & B & CI95\% \\
\hline Kepatuhan & 4,086 & 0,080 & 0,105 & $0,835-24,742$ \\
Paritas & 2,320 & 0,107 & 0,076 & $0,860-4,683$ \\
Jarak Kehamilan & 3,182 & 3,182 & 0,944 & $0,158-5,589$ \\
Umur & 0,471 & 0,471 & 0,177 & $0,045-1,773$ \\
Pendidikan & 1,452 & 1,452 & 0,304 & $0,671-3,598$ \\
\hline
\end{tabular}

Tabel .12 menjelaskan bahwa dari keseluruhan variabel independen, yang paling berisiko terhadap kejadian anemia pada ibu hamil terdapat 1 variabel, yaitu kepatuhan mengkonsumsi tablet Fe dengan nilai odds ratio (OR) 4,086 yang berarti bahwa tidak patuh mengkonsumsi tablet Fe merupakan faktor risiko paling besar diabanding dengan faktor risiko paritas, jarak kehamilan, umur, dan pendidikan. Berdasarkan nilai signifikan diantara keseluruhan variabel independen, tidak ada variabel yang berhubungan dengan kejadian anemia pada ibu hamil. 


\section{Pembahasan}

\section{Kepatuhan Mengkonsumsi Tablet Fe}

Hasil analisis bivariat pada penelitian ini menyatakan adanya hubungan antara kepatuhan mengkonsumsi tablet Fe terhadap kejadian anemia dengan odds ratio (OR) diperoleh nilai = 4,086 (Confedence Interval dengan nilai lower limit $(1,712)$ dan upper limit $(9,749)$. Pada kelompok kasus sebesar $61,1 \%$ tidak patuh mengkonsumsi tablet Fe, sedangkan pada kelompok kontrol sebesar 38,9\%. Maka odds ratio (OR) terjadinya anemia pada ibu hamil, kelompok tidak patuh 4,086 kali lebih berisiko dibandingkan dengan odds ratio terjadinya anemia pada ibu hamil kelompok patuh sehingga peluang untuk menderita anemia lebih besar.

Ibu hamil tidak patuh mengkonsumsi tablet disebabkan banyaknya ibu hamil yang takut gemuk jika mengkonsumsi tablet Fe, aroma yang ada pada tablet Fe tidak sukai oleh kebanyakan ibu hamil. Sebagian besar ibu hamil memiliki stigma jika mengkonsumsi tablet Fe maka bayi yang ada di dalam kandungan akan memiliki berat badan yang berlebihan, sehingga ketika petugas kesehatan memantau ibu hamil, mereka menyembunyikan tablet Fe tersebut.

Petugas kesehatan tidak memantau dengan jangka waktu yg ditentukan agar pemantauan secara akurat dilakukan, hal tersebut menjadikan alasan banyak ibu hamil di wilayah kerja Puskesmas Makale mengalami anemia.

Menurut Medicastore (2007), medication compliance (kepatuhan pengobatan) adalah mengonsumsi obatobatan yang diberikan oleh dokter atau petugas kesehatan lain sesuai dengan waktu dan dosis yang tepat. Pengobatan hanya akan efektif apabila pasien mematuhi aturan dalam penggunaan obat. Apabila ada anjuran untuk menghabiskan obat tersebut, maka harus mengonsumsi obat tersebut sampai habis.

Zat besi (Fe) merupakan mikro elemenyang essensial bagi tubuh. Zat ini terutama diperlukan dalamhemopobesis (pemindahan darah) yaitu dalam sintesa haemoglobin. Disamping itu berbagai jenis enzim memerlukan zat besi sebagai faktor penggiat (Paath, dkk, 2005).

Penelitian ini sejalan dengan penelitian Indah lisfi dkk (2017), tentang hubungan asupan Fe dan vitamin A dengan kejadian anemia pada ibu hamil Trimester III di Puskesmas Air Dingin Kota Padang. Desain penelitian ini studi analitik dengan pendekatan cross sectional, pengambilan sampel dengan cara consecutive sampling dengan jumlah sampel 44. Hasil penelitian ditemukan sebanyak 56,8\% responden mengalami anemia, 59,1\% responden mempunyai asupan Fe dan vitamin A cukup.

2. Paritas

Hasil analisis bivariat pada penelitian ini menyatakan adanya hubungan antara paritas terhadap kejadian anemia dengan odds ratio (OR) diperoleh nilai $=2,320$ (Confedence Interval dengan nilai lower limit $(1,065)$ dan upper limit (5,054). Pada kelompok kasus sebesar 59,0\% memiliki risiko tinggi, sedangkan pada kelompok kontrol sebesar 41,0\%. Maka odds ratio (OR) terjadinya anemia pada ibu hamil, kelompok risiko tinggi 2,320 kali lebih berisiko dibandingkan dengan odds ratio terjadinya anemia pada ibu hamil kelompok risiko rendah sehingga peluang untuk menderita anemia lebih besar.

Ibu hamil di wilayah kerja Puskesmas Makale memiliki pola pemikiran seperti masyarakat pedesaan pada umumnya, tidak banyak mengetahui tentang sistem reproduksi dan kontrasepsi, jadi memiliki banyak anak berarti banyak rejeki tanpa memikirkan masa depan yang baik bagi anak mereka, status ekonomi keluarga, asupan gizi yang akan diberikan pada anak mereka agar tumbuh dan berkembang dengan baik. Setiap kehamilan tidak semua di kehamilan ibu tersebut mengkonsumsi tablet Fe. Dengan paritas yang dimiliki ibu tersebut memiliki risiko tinggi maka terjadinya anemia pada ibu hamil sangat berisiko.

Paritas adalah jumlah yang telah dilahirkan oleh seorang ibu baik lahir hidup maupun lahir mati. Seorang ibu yang sering melahirkan mempunyai resiko mengalami anemia pada kehamilan berikutnya apabila tidak memperhatikan kebutuhan nutrisi. Karena selama hamil zat-zat gizi akan berbagi untuk ibu dan untuk janin yang dikandungnya (Asrul, 2008).

Paritas 2-3 merupakan paritas paling aman ditinjau dari sudut kematian maternal. Paritas 1 dan paritas tinggi (lebih dari 3) Mempunyai angka kematian maternal lebih tinggi. lebih tinggi paritas, lebih tinggi kematian maternal. Resiko pada paritas dapat ditangani dengan asuhan obstetrik lebih baik, sedangkan resiko pada paritas tinggi dapat dikurangi atau dicegah dengan keluarga berencana. Sebagian kehamilan pada paritas tinggi adalah tidak direncanakan (Prawiroharjo, 2007; 23).

Penelitian ini sejalan dengan penelitian Erly Rambu Bita Dambo dkk (2013), tentang faktor-faktor yang berhubungan dengan kejadian anemia ibu hamil trimester iii di puskesmas puweri Kabupaten sumba barat. Desain penelitian ini deskriptif analitik dengan pendekatan cross sectional menggunakan metode survey melalui wawancara dengan menggunakan kuesioner. Hasil penelitian ini menunjukkan bahwa tidak ada hubungan yang signifikan antara jumlah anak dengan kejadian anemia pada ibu hamil.

3. Jarak Kehamilan

Hasil analisis bivariat pada penelitian ini menyatakan adanya hubungan antara jarak kehamilan terhadap kejadian anemia dengan odds ratio $(\mathrm{OR})$ diperoleh nilai $=3,182$ (Confedence Interval dengan nilai lower limit $(1,293)$ dan upper limit $(7,833)$. Pada kelompok kasus sebesar 57,7\% jarak kehamilan memiliki risiko tinggi, 
sedangkan pada kelompok kontrol sebesar 42,3\%. Maka odds ratio (OR) terjadinya anemia pada ibu hamil, kelompok risiko tinggi 3,182 kali lebih berisiko dibandingkan dengan odds ratio terjadinya anemia pada ibu hamil kelompok risiko rendah sehingga peluang untuk menderita anemia lebih besar.

Keinginan memiliki banyak anak merupakan faktor pendukung terjadinya risiko anemia pada ibu hamil, sehingga tidak merencanakan jarak di setiap anak sebagai pertimbangan kesehatan bagi ibu, kurangnya pengetahuan tentang jarak yang baik disetiap kehamilan risiko yang sangat tinggi untuk menderita anemia. Hal tersebut seharusnya menjadi bahan pertimbangan petugas kesehatan dalam memantau dan memperhatikan ibu hamil untuk mengkonsumsi tablet Fe.

Ibu yang baru melahirkan beberapa bulan, sekitar 9-14 bulan, lalu hamil lagi beresiko bagi ibu dan bayinya. Kehamilan adalah masa yang sangat meletihkan dan membutuhkan energi, terutama secara fisik. Keletihan ini makin diperparah jika ibu hamil masih harus merawat dan mengasuh bayi sendiri, sehingga ibu pun membutuhkan energi lebih besar. Belum lagi, jika ibu tak siap punya anak lagi, hamil kembali dapat menimbulkan tekanan psikologis (stres). Ibu hamil yang mengalami stres, menurut penelitian, bisa melahirkan bayi dengan berat badan kurang, lantaran stres mengakibatkan hambatan penyaluran makanan pada janin. Bahkan, bayi yang lahir pun rentan mengalami stres.

Selain faktor perilaku dan psikologis, kehamilan jarak dekat juga rentan mengakibatkan maternal depletion syndrome, yakni terjadinya pengikisan nutrisi ibu oleh janin. Baru saja melahirkan, disambung kehamilan lagi, membuat ibu tak memiliki cukup waktu untuk mengembalikan cadangan nutrisi. Kehamilan jarak dekat juga bisa mengakibatkan kelahiran prematur, penyusutan air susu ibu, bahkan setelah bayi lahir bisa terjadi persaingan antar saudara (Mother And Baby, 2007).

4. Umur

Hasil analisis bivariat pada penelitian ini menyatakan protektif antara umur terhadap kejadian anemia dengan odds ratio $(\mathrm{OR})$ diperoleh nilai $=0,471$ (Confedence Interval dengan nilai lower limit $(0,082)$ dan upper limit $(2,688)$. Pada kelompok kasus sebesar 33,3\% ibu yang memiliki umur $<20$ tahun, sedangkan pada kelompok kontrol sebesar 51,5\%. Maka odds ratio (OR) terjadinya anemia pada ibu hamil, kelompok $>200,082$ kali protektif dibandingkan dengan odds ratio terjadinya anemia pada ibu hamil kelompok umur $<20$ tahun sehingga peluang untuk menderita anemia lebih besar.

Umur ibu pada waktu hamil merupakan salah satu faktor yang mempengaruhi kelangsungan kehamilan karena berkaitan erat dengan perlindungan alat reproduksi. Umur ibu sangat mempengaruhi kesehatan janin serta kualitas bayi yang akan dilahirkan. Ibu yang terlalu muda belum siap untuk memberikan lingkungan yang diperlukan untuk pertumbuhan janin. Sebaliknya umur ibu yang terlalu tua sudah tidak baik lagi untuk pertumbuhan janin. Semakin tua seorang ibu, semakin besar kemungkinan melahirkan anak cacat.

Umur merupakan salah satu faktor resiko pada ibu untuk hamil dan bersalin. Ibu hamil yang berusia kurang dari 20 tahun atau lebih dari 35 tahun akan meningkat resikonya untuk mendapatkan komplikasi kehamilan dan persalinan, demikian juga bayinya (Rifayani, 2005).

5. Pendidikan

Hasil analisis bivariat pada penelitian ini menyatakan adanya hubungan antara pendidikan terhadap kejadian anemia dengan odds ratio $(\mathrm{OR})$ diperoleh nilai $=1,452$ (Confedence Interval dengan nilai lower limit $(0,680)$ dan upper limit $(3,100)$. Pada kelompok kasus sebesar 54,9\% pendidikan rendah, sedangkan pada kelompok kontrol sebesar $45,1 \%$. Maka odds ratio (OR) terjadinya anemia pada ibu hamil, kelompok pendidikan rendah 1,452 kali lebih berisiko dibandingkan dengan odds ratio terjadinya anemia pada ibu hamil kelompok pendidikan tinggi sehingga peluang untuk menderita anemia lebih besar.

Ibu hamil di wilayah kerja Puskesmas Makale sebagian besar memiliki pendidikan sampai SMP dan SMA, hal tersebut terjadi karena kebanyakan masyarakat desa saat wanita memiliki usia sudah bisa menikah, maka dinikahkan. Jadi tidak ada kesempatan oleh wanita tersebut untuk melanjutkan sekolah ke jenjang yang lebih tinggi. Sehingga pengetahuan yang mereka miliki kurang, terutama pengetahuan tentang kesehatan reproduksi dan kontrasepsi.

Tingkat pendidikan ibu hamil dapat menyebabkan keterbatasan dalam upaya menangani masalah gizi dan kesehatannya. Pengetahuan gizi dan kesehatan akan berpengaruh terhadap pola konsumsi pangan. Semakin tinggi pendidikan tentang gizi dan kesehatan, maka semakin beragam pula jenis makanan yang dikonsumsi sehingga dapat memenuhi kecukupan gizi dan mempertahankan kesehatan individu

(Dwi Astuti,2016).

Penelitian ini tidak sejalan dengan penelitian Dwi Astuti (2016), Tentang faktor yang berhubungan dengan kejadian anemia pada ibu hamil di puskesmas undaan LOR Kabupaten Kudus, menjelaskan bahwa kejadian anemia pada ibu hamil lebih banyak ditemukan pada responden yang berpendidikan tinggi sebesar $81,8 \%$ dan tidak terjadi anemia disbanding dengan responden yang berpendidikan rendah. 


\section{Kesimpulan}

Berdasarkan hasil penelitian mengenai faktor risiko penyebab terjadinya anemia pada ibu hamil di Puskesmas Makale tahun 2016 maka ditarik kesimpulan sebagai berikut :

1. Tidak patuh mengkonsumsi tablet Fe 4,086 kali lebih besar berisiko dibandingkan ibu hamil yang patuh mengkonsumsi tablet Fe di Puskesmas Makale tahun 2016.

2. Paritas dengan risiko tinggi 2,320 kali lebih besar berisiko dibandingkan paritas dengan risiko rendah pada ibu hamil di Puskesmas Makale tahun 2016.

3. Jarak kehamilan dengan risiko tinggi 3,182 kali lebih besar berisiko dibandingkan dengan jarak kehamilan dengan risiko rendah pada ibu hamil di Puskesmas Makale tahun 2016.

4. Umur $>20$ tahun 0,471 protektif terhadap kejadian anemia dibandingkan dengan umur $<20$ tahun pada ibu hamil di Puskesmas Makale tahun 2016.

5. Pendidikan rendah 1,452 kali lebih besar berisiko dibandingkan dengan pendidikan tinggi pada ibu hamil di Puskesmas Makale tahun 2016.

\section{Referensi}

Arisman. 2003. Gizi dalam Daur Kehidupan. Bagian Ilmu Gizi Proyek Peningkatan Penelitian. DIKTI Depdiknas. Fakultas Kedokteran USRI, Palembang.

Departemen Kesehatan Propinsi Sulawesi Selatan, 2006. Profil Kesehatan Kota Makassar.

Manuaba IBG, 2000, Ilmu Kebidanan Penyakit Kandungan dan Keluarga Berencana, EGC, Jakarta

Medicastore, 2007, Kampanye Indonesia Bebas Anemia 2006-2008 (seminar), http://info.medicastore.com/index.php?mod=berita\&id=44

Medicastore, 2007, Kepatuhan dalam Pengobatan (Medication Compliance), http://www.anakku.net/forum

Muchtadi, Dedy. 2003. Pengantar Ilmu Gizi. Alfabeta. Bandung.

Mochtar, 2000. Sinopsis Obsetetri Fisiologi Patologi. Jilid I. Buku Kedokteran EGC. Jakarta.

Notoatmodjo, Soekidjo. 2010. Pengantar Pendidikan Kesehatan dan Ilmu Prilaku, Jakarta,

Prawirohardjo Sarwono, 2007., Buku Acuan Nasional Pelayanan Kesehatan Maternal dan Neonatal”. Jakarta. 